\title{
Power Quality Study and Analysis of Different Arc Welding Machines
}

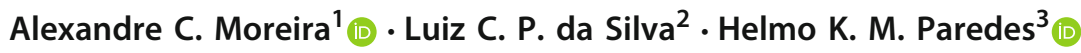 \\ Received: 18 May 2017 / Revised: 3 November 2017 / Accepted: 22 December 2017 / Published online: 8 January 2018 \\ (c) Brazilian Society for Automatics-SBA 2018
}

\begin{abstract}
Electrical welding machines are among the most pollutant loads due to their strong nonlinear behavior. As a result, utilities have established new criteria for connecting welding machines in the grid. One approach that can provide good results in this context is based on modeling this special load and performing simulation studies. In this paper, two different computational models were developed in PSCAD/EMTDC to help the connection evaluation process and power quality studies. Furthermore, instead of a conventional power quality analysis, a power theory for non-sinusoidal voltages and currents is needed to analyze three-phase welding machines. The conservative power theory (CPT) allows an advanced analysis of the load's characteristics as it decouples the power factor into different load conformity factors that are associated with specific characteristics in the load. The analysis and discussions are based on simulations and experimental measurements obtained at the terminals of two different welding machines. The results help to demonstrate the main advantage of the CPT compared to conventional approaches, which is related to its general application for single-phase and three-phase disturbing loads under non-ideal supply voltage conditions.
\end{abstract}

Keywords Conservative power theory $\cdot$ Harmonics $\cdot$ Modeling $\cdot$ Nonlinear loads $\cdot$ Power quality $\cdot$ Welding machine

\section{Introduction}

Welding machines are based on the Joule effect; that is, they use the heat dissipated by a current circulation so as to join two metal parts. This requires the passage of a very high current value, and for this reason, welding machines usually use a step-down transformer in order to reduce the applied voltage to very low values. These loads can be directly con-

Alexandre C. Moreira

amoreira@ufsj.edu.br

Luiz C. P. da Silva

lui@dsee.fee.unicamp.br

Helmo K. M. Paredes

hmorales@sorocaba.unesp.br

1 Telecommunications and Mechatronic Engineering Department - DETEM, Federal University of São João del-Rei (UFSJ), Rodovia MG 443, KM 7, Ouro Branco, MG 36420-000, Brazil

2 Department of Energy and Systems (DSE), School of Electrical and Computer Engineering (FEEC), University of Campinas (UNICAMP), Av. Albert Einstein, 400, Campinas, SP 13083-970, Brazil

3 Institute of Science and Technology, São Paulo State University (Unesp), Av. Três de Março, 511, Sorocaba, SP 18087-180, Brazil nected to low-voltage (LV) distribution networks or through a transformer that can feed several welding machines from a high-voltage (HV) network (Baggini 2008).

During the welding process, short welding intervals (with high current flow) are followed by other no-load operations (normal operation). In each welding process, two voltage steps are produced: one at the time of generating the current and the other at the instant it is cut off. These voltage variations can cause problems in the nearby loads, as the voltage fluctuations may be outside the (minimum and maximum) tolerance limits of the voltage or even produce flicker (Baggini 2008; IEEE 2015; CPFL 2000; Yang and Kratz 2009; Rosentino et al. 2015).

Among all the types of nonlinear loads, the electric welding machine is one of the loads that has the largest impact on the electric power distribution system (Baggini 2008; IEEE 2015; CPFL 2000, 2012; Yang and Kratz 2009; Elektro 2013; De La Rosa 2006; Das 2015). It has a low power factor, large current and voltage fluctuations and significant variations in reactive power; it generates harmonic and current imbalances. These disturbances lead to the deterioration of power quality (PQ) (Silva et al. 2011; Vaidya 2014), violating PQ standards (IEC 2004; IEEE 2014; IEEE P519 2015), affecting the yield and 
quality of nearby loads, and endangering the operation of many users. Many disturbing load accesses lead to serious pollution and can be harmful to the distribution power grid.

In recent decades, welding machines have been increasingly used, mainly due to the development of friendly user inexpensive portable devices. In general, no information is provided to power utilities regarding the existence or operation regime. Given their nonlinear characteristics, this type of device is considered as a potentially disturbing load (IEEE 2015; CPFL 2000, 2012; Yang and Kratz 2009; Elektro 2013; De La Rosa 2006). Thus, depending on the operation mode, a specific load can present intermittent behavior and cause serious PQ disturbances at the local system, such as voltage fluctuations, flicker, harmonics and interharmonics.

Despite the availability of different tools and PQ standards, it has been reported that power utilities usually face considerable practical problems when trying to operate in the presence of this load (CPFL 2000, 2012; Elektro 2013). Therefore, to quantify disturbances caused by welding machines properly, it is important to identify power components (current) that contribute to the degradation of the PQ. Unlike other power formulations that mix the effects of supply voltages and load features (Paredes et al. 2009a,b; Marafão et al. 2009, 2010), the conservative power theory (CPT) can identify power terms (current) associated with each disturbance individually in a "decoupled" way. In fact, the CPT is a theoretical formulation, which analyzes electrical circuits focused on the load behavior (Tenti et al. 2011a,b).

For these reasons, this paper analyzes the characteristics of two different welding machines and the development of their equivalent computational models. Furthermore, using the CPT load conformity factors (Paredes et al. 2012), the machines' impact on PQ is analyzed. Thus, the main contributions of this paper are as follows:

1. To develop a three-phase rectifier welding machine computational model;

2. To develop a three-phase inverter welding machine computational model;

3. To propose analyses of these welding machines adopting means of the CPT, as well as their influence on PQ.

-The rest of this paper is organized as follows: Section 2 presents the welding machines' characteristics. Section 3 describes the welding machines' computational models. Section 4 presents the advantages of using CPT to analyze the welding machines. Some simulation experimental results are given in Sect. 5. Finally, the main conclusions are drawn in Sect. 6.

\section{Welding Machines' Load Characteristics}

An arc welding machine provides the required current and voltages at different stages of the arc process. Initially, high voltage is produced at no load, which is also called opencircuit voltage. When the electrode touches the workpiece, a short-circuit occurs and the current increases suddenly. After the reference current level is reached by the output current, the arc welding machine regulates the output voltage to maintain a constant current, which is required for metal transfer. The voltage produced in the steady state is proportional to the current, which depends on the arc length and electrode diameter. During the transient state of the arcing process, the load varies between open circuit and short circuit (Aksoy 2014; Buso et al. 2009).

According to O'Brien (2004); Casanueva et al. (2011), gas tungsten arc welding (GTAW), or tungsten inert-gas (TIG) welding, is a manual welding process that uses a nonconsumable tungsten electrode to produce the weld. This kind of welding process uses an inverter welding machine. Especially useful for welding thin materials, this method is characterized by a stable arc and high-quality welds. It is often used when welds require the highest quality reliability standards, such as in bicycles, aircrafts, ships and for naval applications.

According to Lincoln (2003), the gas metal arc welding (GMAW), commonly called MIG (metal/inert gas), is a welding process with a continuously fed consumable wire acting as both an electrode and filler metal, along with an inert or semi-inert shielding gas flow around the wire to protect the weld site from contamination. This kind of welding process uses a rectifier welding machine. Nowadays, GMAW is commonly used in the automobile industry for its versatility, speed and quality.

It is for this reason that such loads are mainly used in industrial facilities. As stated earlier, the impacts caused by the operation of these loads on the power system can vary from voltage sags, voltage imbalance and fluctuations to reducing of the acceptable levels of voltage supply in the steady state, mainly resulting in the deterioration of the indices of the supplied voltage quality. This is why it is extremely important for electric companies to identify impacts caused by these loads on the electric distribution system.

\section{Computational Modeling}

Based on voltages and currents measured at TIG and MIG machine terminals, using the PSCAD/EMTDC software, a computational model for these two welding machines was developed. These computational models can be used for studies on power quality, compensation (Kallaste et al. 2008; $\mathrm{Ko}$ and $\mathrm{Gu} 2016$ ) and connection requirements of special 


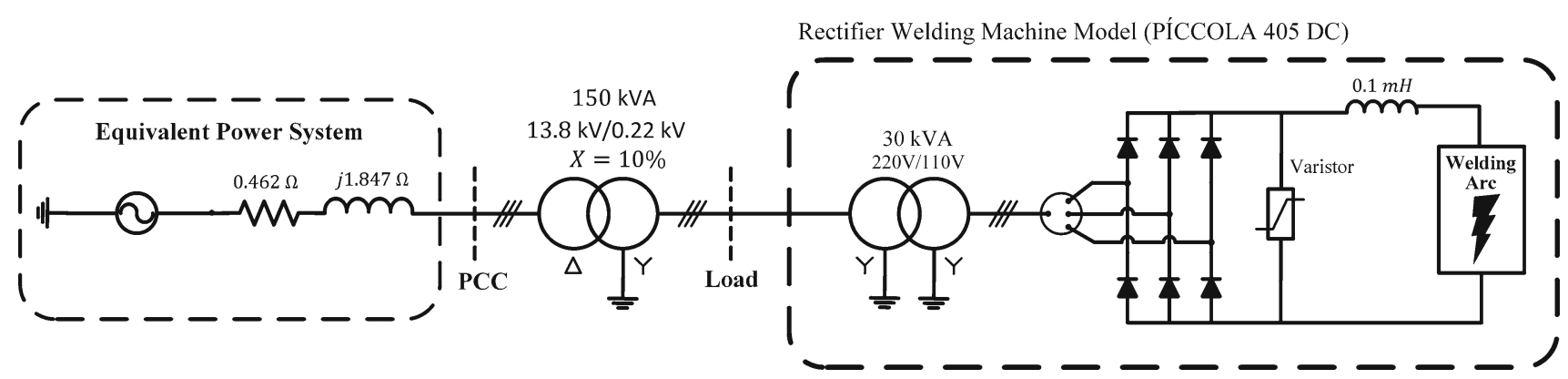

Fig. 1 Electrical circuits for modeling the rectifier welding machine

loads in the electric network (CPFL 2000, 2012; Elektro 2013).

\subsection{Rectifier Welding Machine}

Most industrial welding is done using machines that produce a DC (direct current) arc. Thus, the alternating current (AC) power supply that operates welding machines must be rectified to direct current for the DC arc. These machines can utilize either single-phase or three-phase AC power supply. Two kinds of rectifiers are used in welding machines, selenium rectifiers and silicon-controlled rectifiers.

As described in O'Brien (2004), Norrish (2006), a traditional welding power supply can be broken into a series of elements (components), each of which performs a particular function. A large, iron-core transformer first steps down high-voltage AC (low current) to low-voltage AC (high current). A rectifier circuit is then used to convert the $\mathrm{AC}$ to DC, and finally a filter circuit is used to smoothen the ripples contained in this DC. In this case, the transformer needs to be quite large to work correctly.

Accordingly, in this paper, a rectifier welding machine model was implemented in PSCAD/EMTDC software. Figure 1 shows the power system configuration and rectifier welding machine components. This model is used to represent the MIG welding process. The power system considered to analyze the computational model consists of a three-phase supply, a line impedance and a step-down star-delta transformer responsible for feeding the rectifier welding machine. The short-circuit capacity $\left(S_{\mathrm{SC}}=100 \mathrm{MVA}\right)$ was provided for a Brazilian utility.

The proposed computational model was validated comparing the simulated model currents with experimental measured currents of a $27 \mathrm{kVA} / 220 \mathrm{~V} / 60 \mathrm{~Hz}$ rectifier welding machine (model Píccola 405 DC).

The electric arc and the electrode holder carried or handled by a human (manual welding) are represented by the welding arc block in Fig. 1. This subsystem was implemented following the criteria given in (CPFL 2000). The schematic diagram showing the algorithm for the welding arc genera-

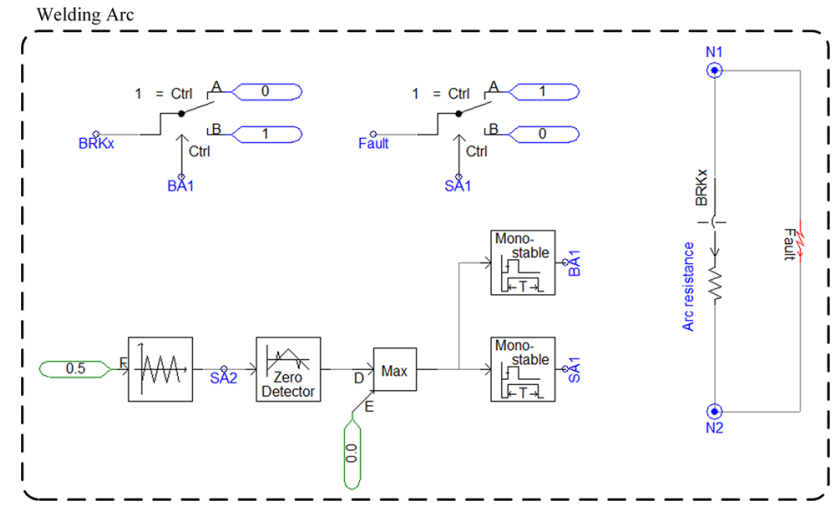

Fig. 2 PSCAD/EMTDC model of electrical arcing and the welding work cycle

tion is presented in Fig. 2. This algorithm allows to emulate (reproduces) the cyclical operation of the welding machine carried out by the welder.

The evolution of the rms voltage and current at the load terminals (computational model) is shown in Fig. 3. Notice that the algorithm allows the rms current evolution (Fig. 3b) to be equal to the one presented in CPFL (2000). Thus, the rms current has the following four stages:

- Stage 1 The welding machine circuit is energized;

- Stage 2 Short circuit between electrodes and workpiece: characterized by the maximum current absorbed;

- Stage 3 Beginning of the arc welding: characterized by intermediary current;

- Stage 4 Beginning of the weld: characterized by the rated current.

In Fig. 4, the load terminal current recorded by the MARH-21 power analyzer (RMS Electronic Systems 2017) is compared with the generated current waveform obtained by the developed model. Seen from the waveforms, the total harmonic distortion is slightly different. This difference is related to the welding machine transformer's (30 kVA, 220/110 V) configuration. As this transformer usually operates saturated, the internal characteristics make its con- 


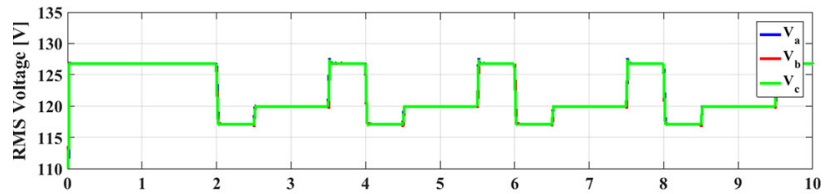

(a)

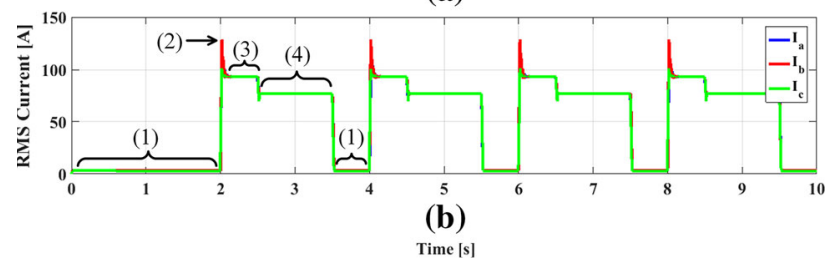

Fig. 3 Parameter evolution at load terminals: a rms voltage, b rms current

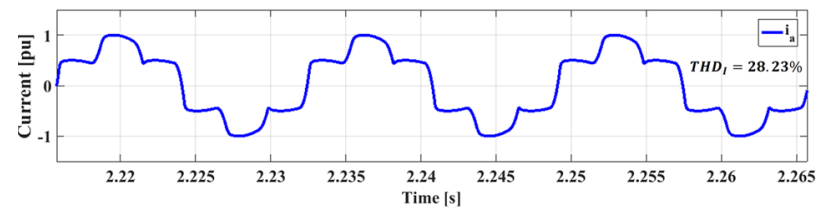

(a)

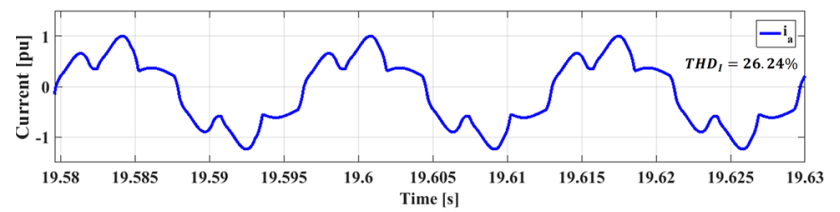

(b)

Fig. 4 Current waveform for the rectifier welding machine: a Simulated, b measured

figuration process a very complex and difficult task to be performed. The parameters used in the computational model were collected from a real welding machine.

\subsection{Inverter Welding Machine}

Currently, due to technological advantages from inverters, the inverter welding machine has become a very popular choice. Inverter control systems, when applied to welding, can develop compact power sources with low energy requirements.
As described in O'Brien (2004); Norrish (2006); Wang et al. (2011); Wang and $\mathrm{Wu}$ (2015), inverter welding machines use a series of rectifiers and solid-state switches to convert the AC input supply into DC output, which should provide a high current for welding. Thus, the AC voltage supply $(220 \mathrm{~V})$ is rectified and filtered to produce voltage DC (three-phase full bridge rectifier and LC filter).

The single-phase full bridge inverter then converts the filtered DC back to an alternating voltage at a frequency of approximately 5-200 kHz. Thus, the current and voltage can be controlled using smaller magnetic devices than traditional technologies (large iron-core transformers). Therefore, this machine weighs considerably less and also consumes less electricity than a rectifier welding machine (traditional welding power supply).

The transformer then converts the low AC current (at high frequency) into high DC current, before being rectified again to adjust the required welding current. Finally, the control system monitors input and output to ensure constant current or constant voltage (stable welding characteristics).

Figure 5 shows the electrical circuit of an inverter welder machine model. This model is used to represent the TIG welding process. Similar to the previous model (Fig. 1), the power system and parameter configuration of this computational model were performed by compiling and gathering data from utilities, manufacturers and industries that operate welding machines.

Figure 6 shows the results of the simulation and measurement of the current waveform for an inverter welding machine. As can be observed, the waveforms are close. The same happens with current harmonic distortion. Due to the presence of the frequency inverter, the current drained from the grid has a nonlinear characteristic and a high distortion.

\section{Advantages of Applying CPT for Analyze Welding Machines}

Among the various disturbing loads, the electric welding machine is a serious cause for concern for utilities given

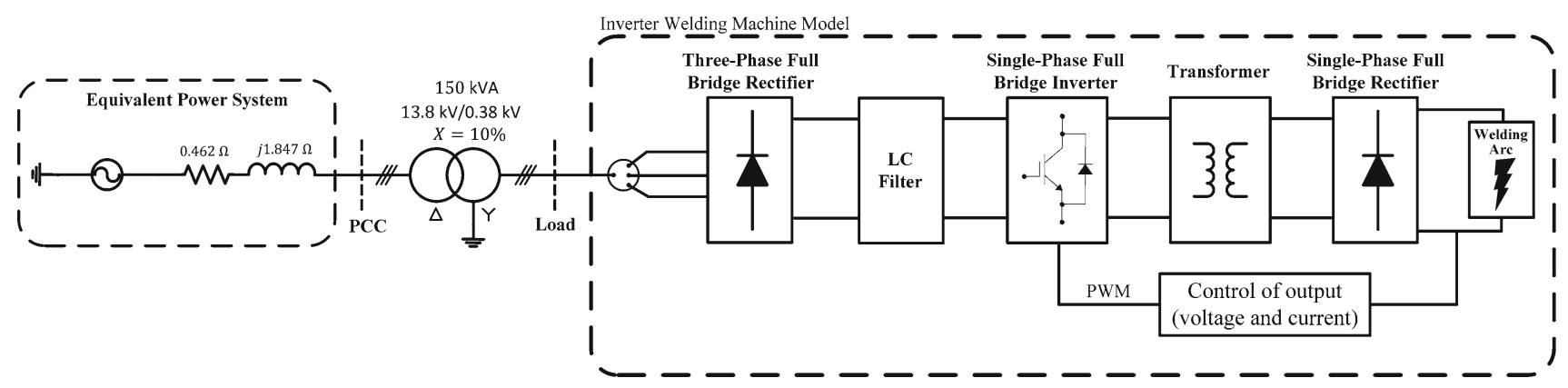

Fig. 5 Basic electrical circuits for modeling the inverter welding machine 


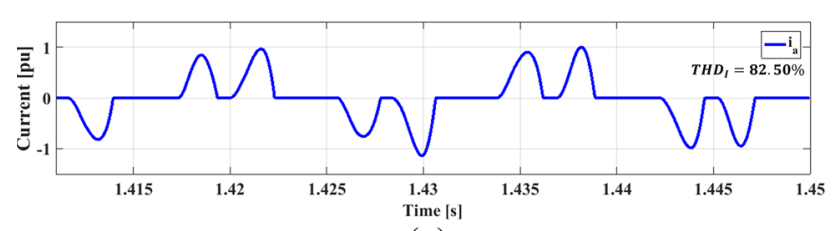

(a)

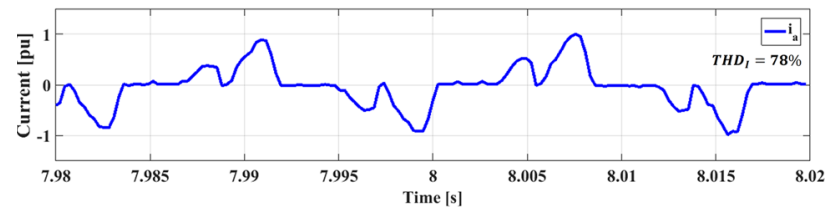

(b)

Fig. 6 Current waveform for the inverter welding machine: a Simulated, $\mathbf{b}$ measured

its high disturbing characteristics and low power factor. This equipment, when connected indiscriminately (without previous warning) to the branches of the electrical systems, causes changes in the network voltage. The energy supply to this equipment (consumers) that cause disturbances in the supply system, due to the high disturbing potential, jeopardizes not only the consumer responsible for the disturbance, but also other consumers connected to the same. In addition, if it is considered that weak networks (those with a high-impedance line, such as microgrids) can occur, for example, significant voltage distortions at the point of common coupling (PCC), because of non-sinusoidal currents or even causing imbalances due to nonlinearities between the voltages and currents. Thus, as the consumer owns the nonlinear load, he/she will also be responsible for the disturbances injected into the electrical system. However, if the consumer is within permissible limits concerning the disturbances, it is undoubtedly the utility's responsibility for correcting the disturbances. However, accountability is not so simple, as a linear load can behave as a nonlinear load if the supply voltage is distorted. It is very difficult for power utilities to inspect the connection of this type of equipment, which is connected without previous warning, mainly in the low-voltage networks, making a preliminary study impossible that avoids the propagation of disturbances and the possible problems associated with this type of equipment.

To quantify these disturbances properly, it is important to identify power components (current) that contribute to the degradation of the $\mathrm{PQ}$.

For these reasons, a suitable power theory to analyze the impact of nonlinear loads under non-sinusoidal operation is an important choice to obtain more information about the power properties of the welding machine, which can be useful to improve the analysis, not only in the power quality and load connection impact, but also in the harmonic compensation and power factor correction. The CPT (Tenti et al. 2011b, 2010) is a time-domain approach that can be applied to single- phase and three-phase nonlinear loads under non-sinusoidal conditions (Tenti et al. 2014; Souza et al. 2013). The main motivation for using CPT in this article is due to the fact that CPT can identify necessary terms associated with each disorder individually in a decoupled way. In fact, the CPT is a theoretical formulation which analyzes electrical circuits focused on the load behavior (Tenti et al. 2011a,b).

It is well known that welding machines are single-phase or three-phase nonlinear loads with very large time-varying behaviors. Thus, by using CPT, the different current terms (or power) can be associated with the characteristics of the different types of welding machines. In other words, reactive, unbalanced and harmonic currents that are generated by the welding machines when welding can be identified. The main power and current plots of the CPT are summarized below.

The apparent power is:

$A=\boldsymbol{V} \cdot \boldsymbol{I}$

where

$\boldsymbol{V}=\sqrt{V_{a}^{2}+V_{b}^{2}+V_{c}^{2}}$

and

$\boldsymbol{I}=\sqrt{\boldsymbol{I}_{a}^{2}+\boldsymbol{I}_{r}^{2}+\boldsymbol{I}_{v}^{2}}$

Equations (2) and (3) provide the collective rms value of the voltage $(\boldsymbol{V})$ and current $(\boldsymbol{I})$. Notice that (2) is a function of the phase voltages, while (3) is a function of the collective rms value of the active current $\left(\boldsymbol{I}_{a}=\sqrt{I_{a a}^{2}+I_{a b}^{2}+I_{a c}^{2}}\right)$, collective value of the reactive current $\left(\boldsymbol{I}_{r}=\sqrt{I_{r a}^{2}+I_{r b}^{2}+I_{r c}^{2}}\right)$, and collective rms value of the void (distortive) current $\left(\boldsymbol{I}_{v}=\sqrt{I_{v a}^{2}+I_{v b}^{2}+I_{v c}^{2}}\right)$.

From (3), as all the current components are orthogonal, the collective rms value of the current is decomposed as:

$\boldsymbol{I}^{2}=\boldsymbol{I}_{a}^{2}+\boldsymbol{I}_{r}^{2}+\boldsymbol{I}_{v}^{2}=\boldsymbol{I}_{a}^{b^{2}}+\boldsymbol{I}_{r}^{b^{2}}+\boldsymbol{I}^{u^{2}}+\boldsymbol{I}_{v}^{2}$

where $\boldsymbol{I}_{a}^{b}$ is the collective rms value of the balanced active current; $\boldsymbol{I}_{r}^{b}$ is the collective rms value of the balanced reactive current; $\boldsymbol{I}^{u}$ is the collective rms value of the unbalanced current; $\boldsymbol{I}_{v}$ is the collective rms value of the void current.

The undesired currents (reactive, imbalanced and harmonic) that each type of welding machine consumes from the electric network during the operation cycle of the machine from the current decomposition are shown in (4).

Multiplying (4) by the square of the collective rms value of the voltage, the apparent power is decomposed into:

$A^{2}=\boldsymbol{V}^{2} \boldsymbol{I}_{a}^{b^{2}}+\boldsymbol{V}^{2} \boldsymbol{I}_{r}^{b^{2}}+\boldsymbol{V}^{2} \boldsymbol{I}^{u^{2}}+\boldsymbol{V}^{2} \boldsymbol{I}_{v}^{2}$ 
where

$P=\boldsymbol{V} \boldsymbol{I}_{a}^{b}$

is the active power.

$Q=\boldsymbol{V} \boldsymbol{I}_{r}^{b}$

is the reactive power. As discussed in Tenti et al. (2010), this power term is influenced by the line frequency and voltage distortion. Only in sinusoidal condition (7) does it have the same value as the reactive power defined by standard STD 1459 (IEEE 2010).

$N=\boldsymbol{V} \boldsymbol{I}^{u}$,

is the unbalanced power. This power term is uniquely associated with unbalanced load behavior. In single-phase circuits, this component disappears.

$D=\boldsymbol{V} \boldsymbol{I}_{v}$

is the void (distortive) power. This power term is related to the nonlinearity between the voltage and current.

Finally, the power factor is computed as:

$\lambda=\frac{P}{A}=\frac{P}{\sqrt{P^{2}+Q^{2}+N^{2}+D^{2}}}$

In (10), it can be observed that the power factor relates the active power with all the other power terms through the apparent power. $\lambda$ results in unitary only if the load is purely resistive and balanced. Otherwise, the presence of energy storage elements, unbalanced loads and nonlinearities will reduce the power factor. Complementary analyses of the current terms and the related power terms can be found in Tenti et al. (2011b).

In addition, in Paredes et al. (2012), based on the previous definition of the current/power terms, the authors proposed a set of load conformity factors. These factors relate the disturbances (effects) of a generic load, allowing load characterization under different operating conditions (Souza et al. 2013). Next, such definitions are described to discuss their application for the study and analysis of welding machines.

Distortion (nonlinearity) factor $\left(\lambda_{D}\right)$ is defined as:

$\lambda_{D}=\frac{D}{A}$

This factor relates the voltage and current's nonlinearities (presence of distortive power), in other words, current terms which do not contribute to active power and reactive power.

Table 1 Rectifier welding machine specifications (Píccola 2017)

Input voltage

Ampere input at rated load

Frequency

Maximum open-circuit voltage

Welding amperage range

Arc voltage at $400 \mathrm{~A}$

Rated power

Reactivity factor $\left(\lambda_{Q}\right)$ is defined as:

$\lambda_{Q}=\frac{Q}{\sqrt{P^{2}+Q^{2}}}$

This factor indicates the phase shift between the voltage and current under non-sinusoidal condition.

The unbalance factor $\left(\lambda_{N}\right)$ is defined as:

$\lambda_{N}=\frac{N}{\sqrt{P^{2}+Q^{2}+N^{2}}}$

This factor represents the imbalanced load behavior. In case of a single-phase load, this factor does not matter.

Observe that each one of these factors is directly related to the load characteristics. Thus, the CPT load factors can identify and quantify the disturbing load decoupled from the disturbances. Aiming to achieve a general analysis, this paper proposes to use the CPT current/power terms and factors to assess the behavior of two different arc welding machines.

\section{Experimental Results}

In order to conduct the welding machines' analysis adopting CPT, the three-phase voltages and currents were measured at the rectifier welding machine and inverter welding machine terminals. The data were registered using a MARH-21 power analyzer (RMS Electronic Systems 2017), considering 64 samples per cycle. The aim is to show how the CPT can provide an understanding and decoupled interpretation of the disturbances caused by the welding machines' behavior. In addition, the impacts of each disturbance in the power quality assessment can be identified.

\subsection{Analysis of the Rectifier Welding Machine}

In this section, we analyze and discuss the CPT current/power terms and factors for the rectifier welding machine connected to the electrical system shown in Fig. 1. The main parameters of the three-phase rectifier welding machine are indicated in Table 1. 


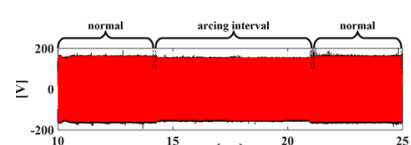

(a)

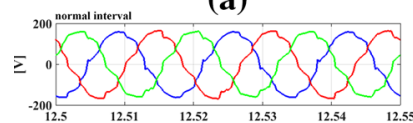

(c)

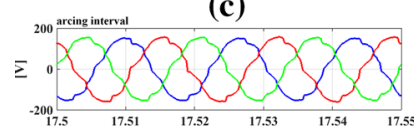

(e)

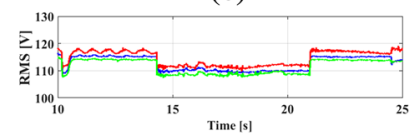

(g)

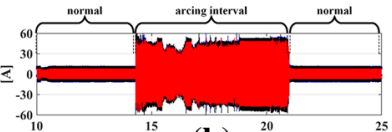

(b)

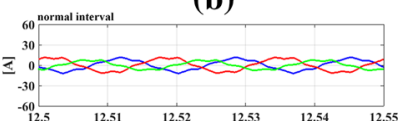

(d)

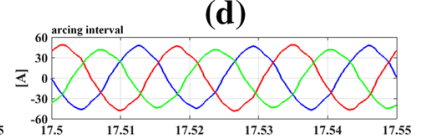

(f)

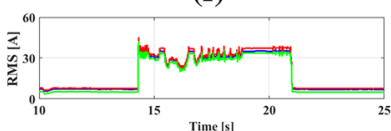

(h)

Fig. 7 Voltages (left) and currents (right) measured at rectifier welding machine terminals: from top to bottom, waveforms at total interval, zoom on the normal interval, zoom on the arcing interval, rms values

Figure 7 shows the measured rectifier welding machine load terminal voltages and currents (instantaneous and rms values). Observe that it is possible to identify when the welding machine is energized, when there is no welding production (normal portion) and the weld interval (arcing period). By zooming in the normal and arcing intervals, it can be seen that the supply voltage waveform (Fig. 7, on the left) is distorted. Moreover, notice that the rms voltage drops during the arcing period.

On the other hand, in Fig. 7, on the right, this machine actually has a nonlinear behavior, because the current waveforms are non-sinusoidal (see zoom intervals). The rms values of the currents, during the arcing interval, reach approximately $40 \mathrm{~A}$. Besides, notice that for all intervals there are current imbalances.

The instantaneous currents presented in Fig. 7 (right) are decomposed into CPT current components. The results of the current decomposition are shown in Figs. 8 and 9. Observe that all CPT current terms increased during the arcing interval.

Figure 8 shows that the balanced active and reactive terms increased significantly. The collective rms value of the balanced reactive current $\left(\boldsymbol{I}_{r}^{b}\right)$ was approximately six times higher than the normal period (from 10 to $60 \mathrm{~A}$ ).

Figure 9 shows the imbalance and distortion disturbance caused by the rectifier welding machine. The collective rms value of the unbalanced current $\left(\boldsymbol{I}^{u}\right)$ registered an increase from $3 \mathrm{~A}$ to approximately $6 \mathrm{~A}$ (double) and the nonlinearities between voltages and currents $\left(\boldsymbol{I}_{v}\right.$ void current) also increased. Thus, this welding machine will have various effects on the grid, affecting the distribution grid voltages' quality, increasing the line losses, harmonic current propagation and imbalances in the power system.

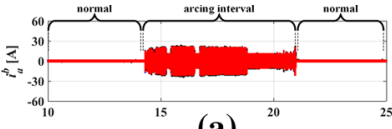

(a)

(c)

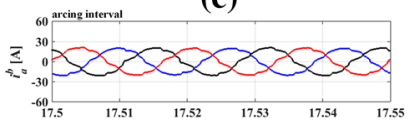

(e)

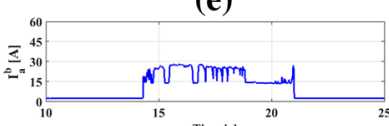

(g)

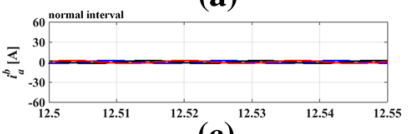

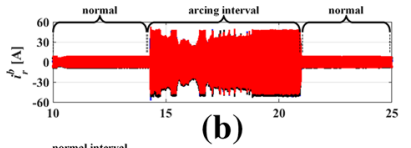

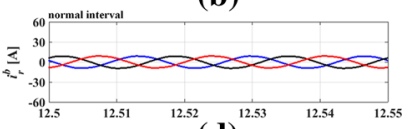

(d)

(f)

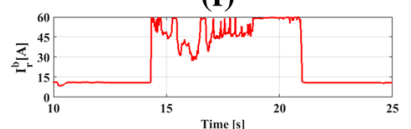

(h)

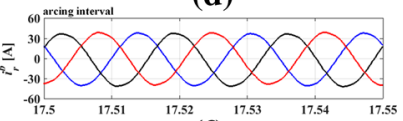

Fig. 8 CPT, balanced active current (left) and balanced reactive current (right) decomposed for the rectifier welding machine: from top to bottom, waveforms at total interval, zoom on the normal interval, zoom on the arcing interval, collective rms values

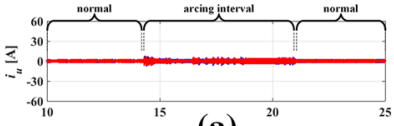

(a)
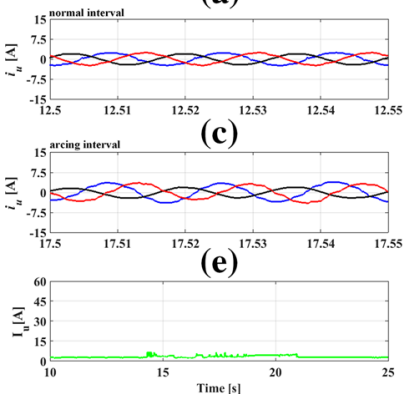

(g)

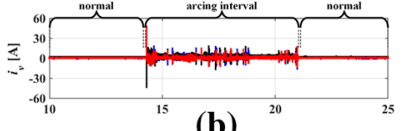

(b)

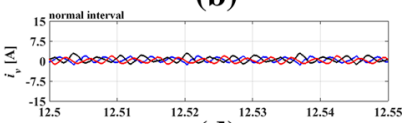

(d)

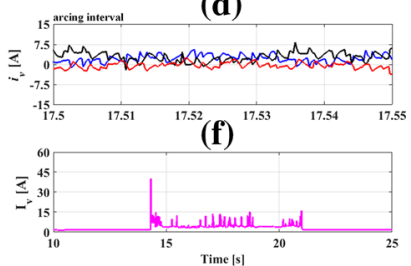

(h)
Fig. 9 CPT, unbalanced current (left) and void current (right) decomposed for the rectifier welding machine terminals: from top to bottom, waveforms at total interval, zoom on the normal interval, zoom on the arcing interval, collective rms values

As previously mentioned, the CPT is a time-domain approach, in which the currents and powers are decomposed into plots related to the behavior of the circuit under analysis. However, an analysis can be made of the harmonics and interharmonics, produced by the rectifier welding machine, through a frequency-domain analysis.

Figure 10 shows the frequency spectrum of the voltage and current waveform (phase $a$ ) during the normal and arcing interval. Therefore, an observation window of 120 cycles was chosen, and a sampling frequency of $3840 \mathrm{~Hz}$ was chosen (4.27 s of observation window and 7680 samples). This choice leads to a spectral resolution of $0.5 \mathrm{~Hz}$, so as to identify interharmonic frequencies. The voltage spectrum for the normal interval (Fig. 10a) shows that the harmonic content of the 3rd $(180 \mathrm{~Hz}), 5$ th $(300 \mathrm{~Hz})$ and 7 th $(420 \mathrm{~Hz})$ order is the most representative with $2.21,3.33$ and $3.71 \%$, respectively, of the 


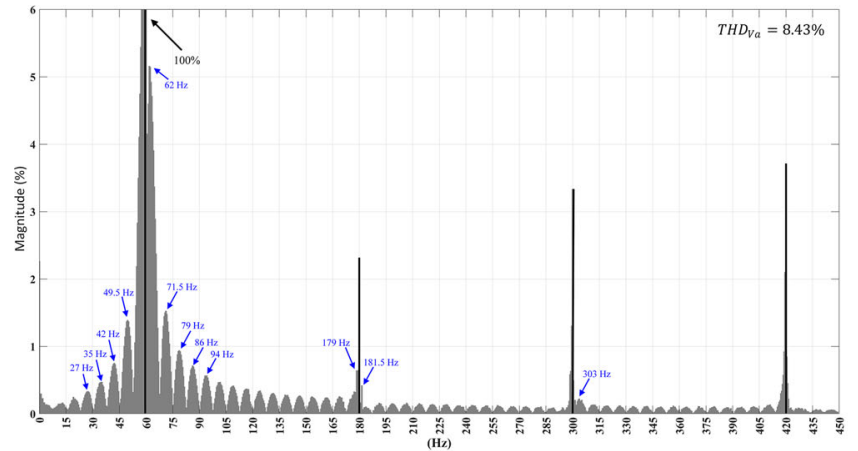

(a)

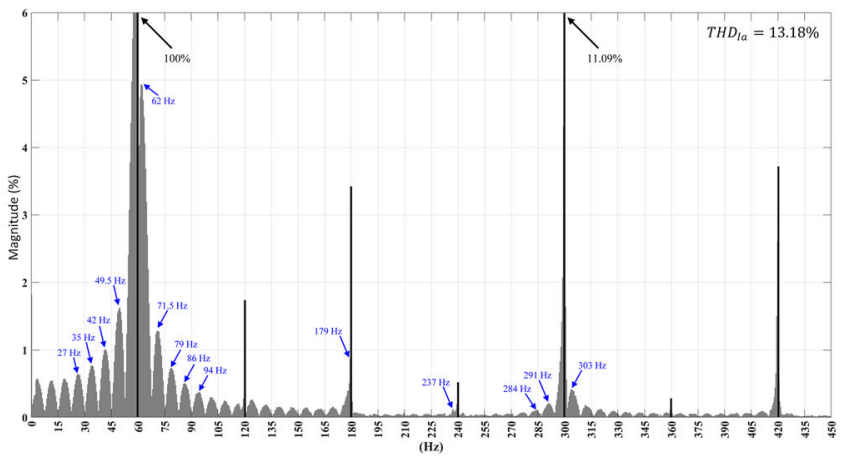

(c)

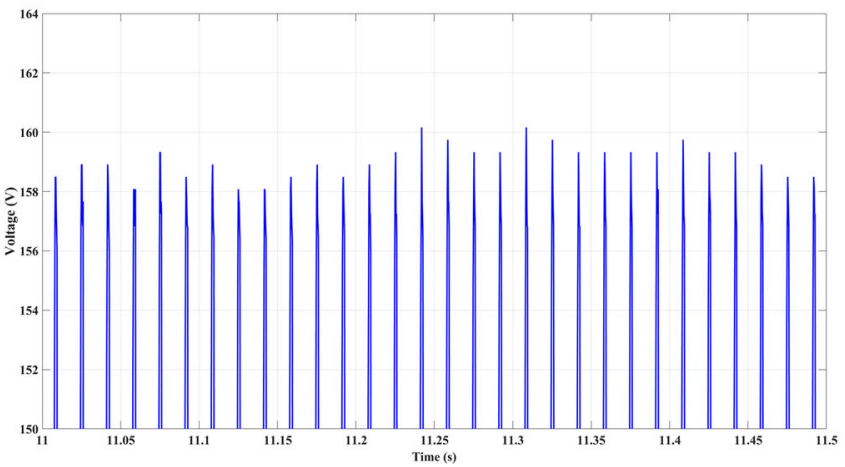

(e)

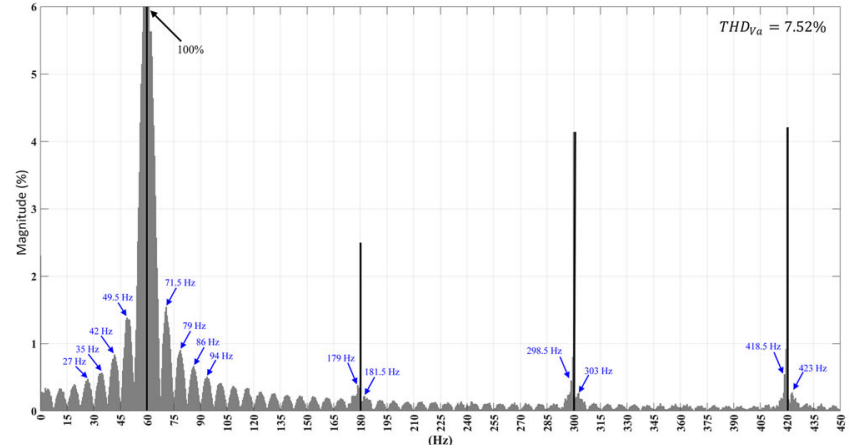

(b)

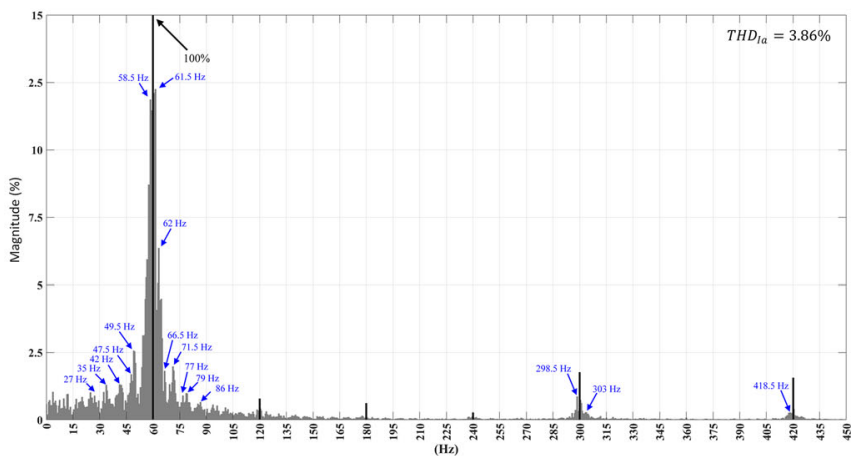

(d)

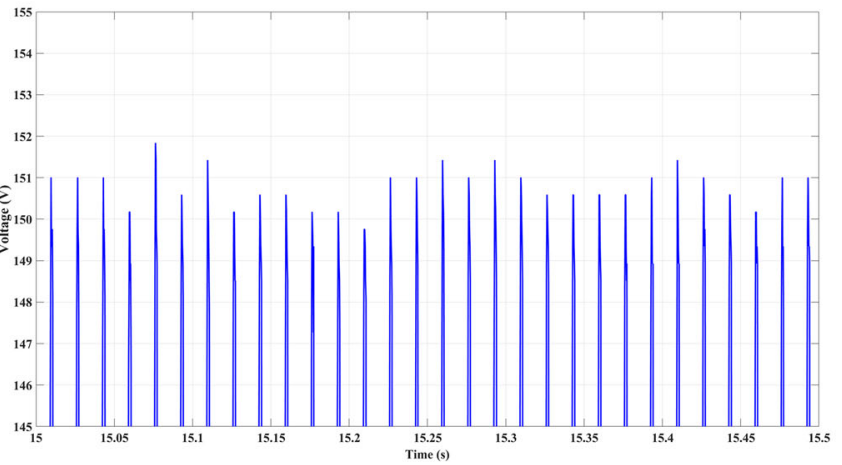

(f)

Fig. 10 Voltage and current spectrum and voltage fluctuation at the rectifier welding machine terminals: on the left, normal interval and on the right, arcing interval

fundamental. In addition, there is spectral leakage (intrinsic to the Fourier transform). The total voltage harmonic distortion of phase $a\left(\mathrm{THD}_{\mathrm{V} a}\right)$ before welding is $8.43 \%$. While welding, there is a reduction of $\mathrm{THD}_{\mathrm{V} a}$ (Fig. 10b), however, with an increase of the 5th and 7th harmonic amplitudes. Regarding the current, as shown in Fig. 10c, the presence of the 5th order represents $11.09 \%$ of the fundamental. Unlike the voltage distortion, the current distortion considerably reduces during the arcing interval (see Fig. 10d).

The presence of components in the voltage and current with non-multiple frequencies of the fundamental frequency of the electric network is observed in Fig. 10a-d. The presence of interharmonics with relevant amplitudes in the vicinity of the fundamental frequency is shown in Fig. 10c, d. The presence of even harmonics in the current (120, 240 and $360 \mathrm{~Hz}$ ) can also be seen. Moreover, the presence of interharmonic voltage components, superimposed on the fundamental signal $(60 \mathrm{~Hz})$, as shown in Fig. 10a, b, causes a modulation in the magnitude of the supply voltage of the rectifier welding machine, as shown in Fig. 10e, f.

Figure 11 shows the CPT power terms and load conformity factors for the rectifier welding machine. Figure 11, on the left, shows the increase in active power consumption (six times), mainly due to strong energy demand by the machine during the welding. The reactive power consumption was also incremented six times (from 2 to 12 kvar). The void (distortion) power, related to the nonlinear load behavior, rose slightly. Unlike the active, reactive and void power $(P$, 


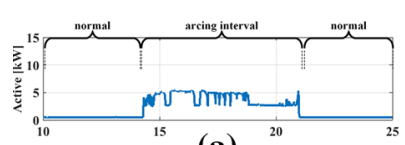

(a)

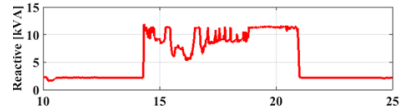

(c)

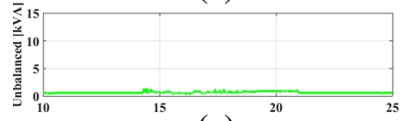

(e)

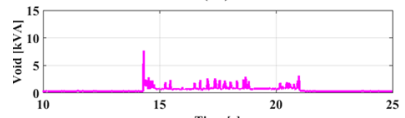

(g)

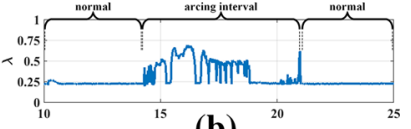

(b)

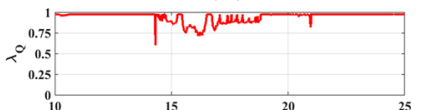

(d)

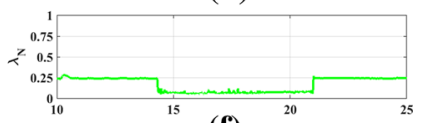

(f)

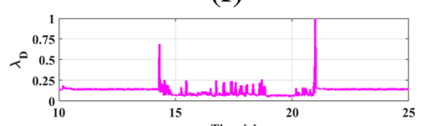

(h)
Fig. 11 CPT power terms (left) and load conformity factors (right) for the rectifier welding machine

$Q$ and $D$ ), the unbalanced power $(N)$ did practically not increase over the welding period. Finally, notice that when the machine is in the normal period, its behavior is practically inductive. This is due to the presence of the large transformer $(Y-Y)$ at the input of the rectifier (see Fig. 1).

The evolution of the load performance factors is shown in Fig. 11, on the right. While the power factor increases over the welding period, the other factors (reactivity, unbalance and distortion) decrease. Notice that this machine has an extremely low power factor $(0.25)$ and high values of load conformity factors $\left(\lambda_{Q}=97 \%, \lambda_{N}=25 \%\right.$ and $\left.\lambda_{\mathrm{D}}=14 \%\right)$ prior to the application of the solder. Throughout the welding process, the power factor rises to 0.74 inductive, since the active power consumption increased. For the same reason (increase of $P$ ), the load factors $\left(\lambda_{Q}, \lambda_{N}\right.$ and $\left.\lambda_{\mathrm{D}}\right)$ decreased. Notice that the $\lambda_{\mathrm{D}}$ has the same value as the $\mathrm{THD}_{I}$ (see Fig. 10). However, unlike $\mathrm{THD}_{I}$ (which is calculated per phase), $\lambda_{D}$ represents an equivalent distortion value of the whole load. The same applies to $\lambda_{N}$ (unbalanced factor) and $\lambda_{Q}$ (reactivity factor) that are different to the traditional unbalanced factors (based on the fundamental sequences components;,+- and 0 ) and the displacement factor (valid only for sinusoidal condition).

This shows that the rectifier welding machine had a much more disturbing effect off-weld than during the welding. This occurred due to the machinery's design and construction (see Fig. 1). On the other hand, during the welding process, the active power consumption increased considerably, due to the electrical arc which demands high currents, that cause the load conformity factors (disturbances) to decrease and the power factor to increase. Nonetheless, in any case, to greater or smaller extent, the disturbances still continue to circulate through the power system affecting the power quality.

It can be concluded, adopting the CPT approach (currents, power and factors), that the rectifier welding machine
Table 2 Welding inverter machine specifications (CST 250 2017)

\begin{tabular}{ll}
\hline Input voltage & $230 / 460 / 575 \mathrm{~V}$ \\
Ampere input at rated load & $21.7 / 11.4 / 9.2 \mathrm{~A}$ \\
Frequency & $60 \mathrm{~Hz}$ \\
Maximum open-circuit voltage & $77 \mathrm{~V}$ \\
Welding amperage range & $5-250 \mathrm{~A}$ \\
Arc voltage at 200 A & $28 \mathrm{~V}$ \\
Rated power & $9.1 \mathrm{kVA}$ \\
\hline
\end{tabular}

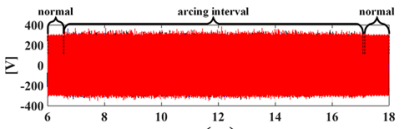

(a)

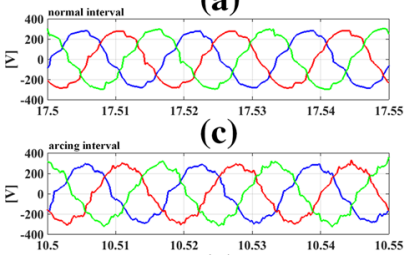

(e)

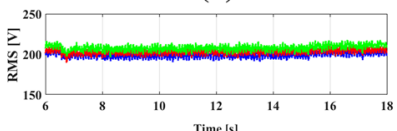

(g)

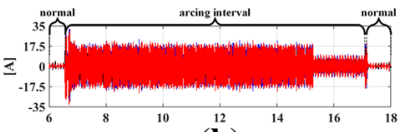

(b)

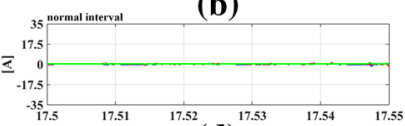

(d)

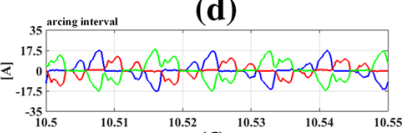

(f)

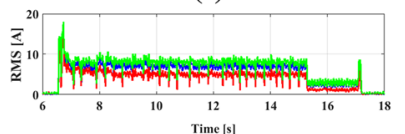

(h)
Fig. 12 Voltages (left) and currents (right) measured at inverter welding machine terminals: from top to bottom, waveforms at total interval, zoom on the normal interval, zoom on the arcing interval, rms values

will produce unbalances, harmonic and interharmonic distortions, high reactive consumptions and a low power factor. These disturbances can therefore propagate to other locations in the power systems and eventually return to the source. Therefore, regarding power quality, loads connected to the same bus may not operate properly or may be damaged.

\subsection{Analysis of the Inverter Welding Machine}

Currently, inverter welding machines are preferred to conventional welding machines due to their high efficiency, high performance and lower volume. It should be stressed that this machine can be directly connected to an LV distribution system.

Similar to the previous section, the CPT current/power terms and factors are analyzed and discussed for an inverter welding machine connected to the electrical system of Fig. 5 . The main parameters of the three-phase welding inverter machine are listed in Table 2.

The inverter welding machine voltage and current waveforms and rms values are shown in Fig. 12. Due to the lower power level when compared with the rectifier welding machine, this machine does not produce a voltage drop (Fig 12, on the left). During the normal interval (before the 


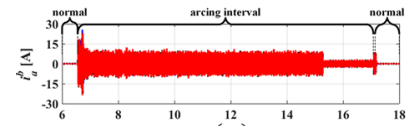

(a)

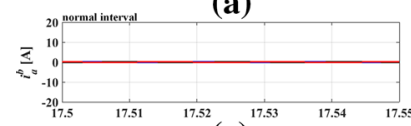

(c)

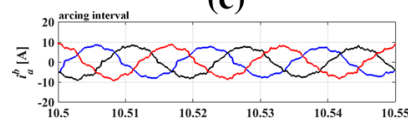

(e)

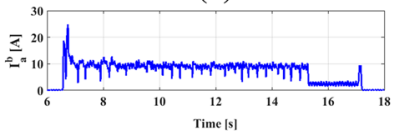

(g)

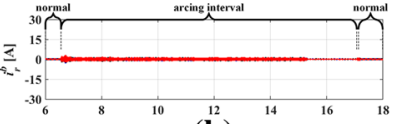

(b)

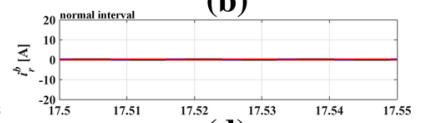

(d)

(f)

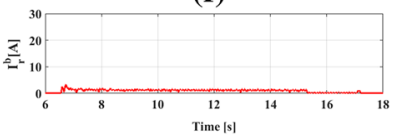

(h)

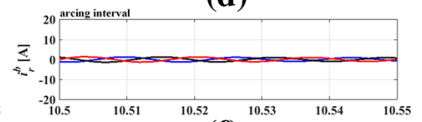

Fig. 13 CPT, balanced active current (left) and balanced reactive current (right) decomposed for the inverter welding machine: from top to bottom, waveforms at total interval, zoom on the normal interval, zoom on the arcing interval, collective rms values

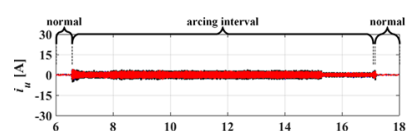

(a)
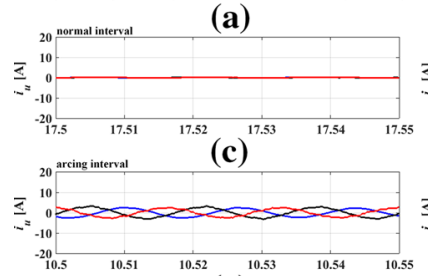

(e)

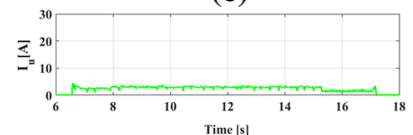

(g)

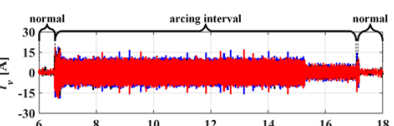

(b)

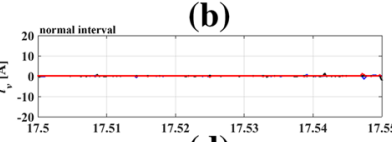

(d)

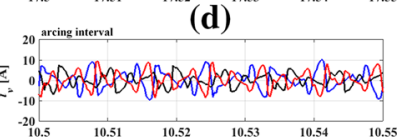

(f)

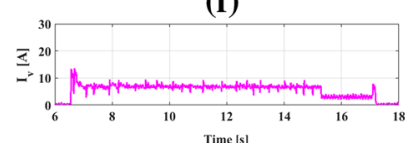

(h)

Fig. 14 CPT, unbalanced current (left) and void current (right) decomposed for the inverter welding machine terminals: from top to bottom, waveforms at total interval, zoom on the normal interval, zoom on the arcing interval, collective rms values

welding), the current magnitude is close to zero (Fig. 12 on the right). However, due to its nonlinear characteristics, it generates higher levels of harmonic currents during the welding.

As in the previous session, the instantaneous currents presented in Fig. 12, on the right, are decomposed into CPT current components, as shown in Figs. 13 and 14. Observe that all current terms are present during the arcing interval. This shows that the machine requires reactive, unbalanced and harmonic currents to ensure the welding, as well as its own operation.

In the zoom interval, Figs. 13 and 14, the CPT current components for normal operation (non-arcing) and arcing interval, respectively, are presented. Notice that the nonlinearities (harmonics) and imbalance produced by the machine

are present. From the rms collective values, it can be observed that these values for the arcing interval are higher than for the normal interval. On the other hand, the nonlinearities (harmonics) reach values close to the balanced active currents. This high production of harmonics is due to the presence of the inverter in the machinery's design and construction (see Fig. 5). Thus, the decoupled CPT current components can identify the welding occurrence and their impact on each disturbance individually. Furthermore, it can be observed that the amount of such values depends on the welding intensity.

In Fig. 15, the harmonic frequency spectrum of the phase $a$ voltage and current is illustrated. Notice that before welding, the voltage is distorted and the amount of the 3rd, 5th and 7 th harmonic reaches $2.31,3.33$ and $3.714 \%$, respectively (Fig. 15a). During the arcing interval, the voltage distortion increases from 9.47 (Fig. 15b) to 10.26 (Fig. 15b), whereas the current distortion decreases (Fig. 15c). During the arcing interval, the $3 \mathrm{rd}$, 5th and 7 th harmonics are present. As can be seen, the 5 th harmonic is almost $50 \%$, the 3 rd is around $40 \%$ and the 7 th is approximately $28 \%$, as shown in Fig. $15 \mathrm{~d}$. As a result, the current waveform is highly distorted as shown in Fig. 12, on the right.

As in the rectifier welding machine, the inverter welding machine also features interharmonics as shown in Fig. 15a-d. In the case of the currents, before the machine operator starts welding, amplitudes around $30 \%$ are verified for frequencies 71 and $190.5 \mathrm{~Hz}$ (Fig. 15c).

In addition, the presence of the harmonic pairs (120, 240, $360 \mathrm{~Hz}$ ) must be emphasized, as well as the interharmonics located in the regions near these frequencies. During the electric welding application, there is a small reduction in the total current harmonic distortion $\left(\mathrm{THD}_{I a}\right)$.

Figure $15 \mathrm{e}$, f shows 60 cycles of the supply voltage at the inverter welding machine terminals before and after the machine operator starts welding. A fluctuation of the voltage signal can be observed. In addition, it can be noted that the amplitude of this voltage is modulated due to the presence of interharmonic components with frequencies below $120 \mathrm{~Hz}$ present in the voltage (Fig. 15a, b).

Figure 16 summarizes the CPT power terms and the load conformity factors measured for the inverter welding machine. It can be seen that before the arcing interval all power terms practically are null. However, during the welding (arcing interval) the high demand for active power is due to the electric arc. The reactive $(Q)$ and unbalanced $(N)$ power consumption are minimal, and the distortion power (D) consumption reaches values close to the active power (see Fig. 16, on the left).

From Figs. 11 and 16 (both, on the left), it can therefore be concluded that the reactive power demand of the inverter machine is much smaller than the rectifier machine, unlike the void power consumption, which is much higher for the inverter machine and much smaller for the rectifier machine. 


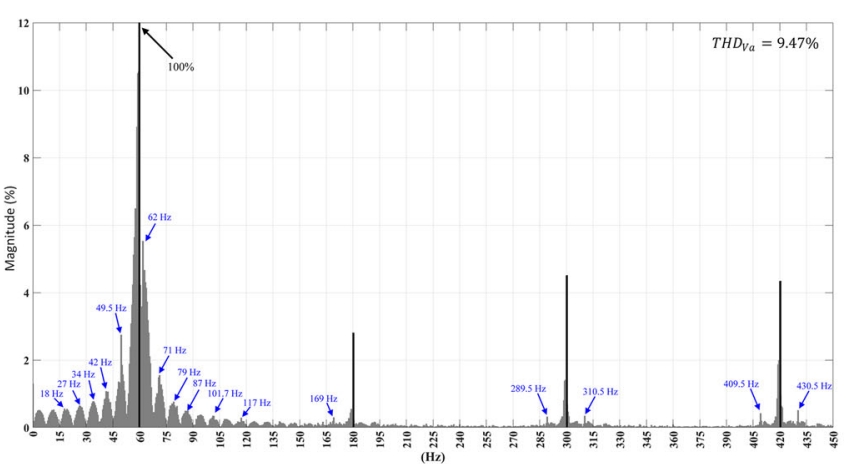

(a)

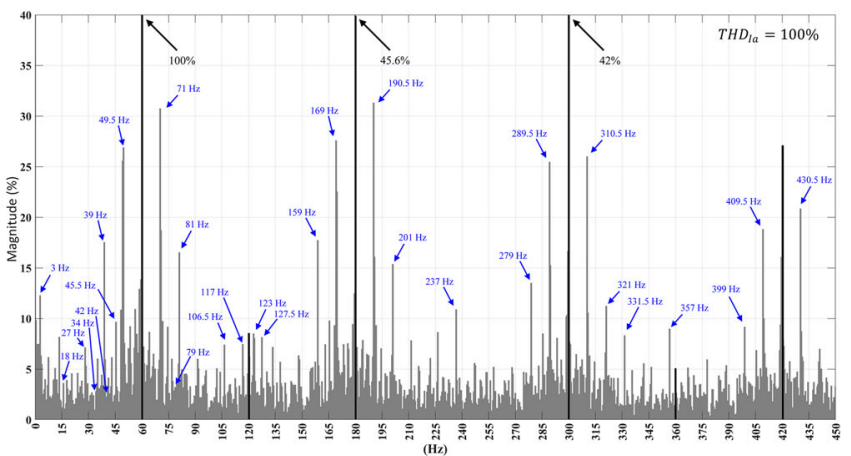

(c)

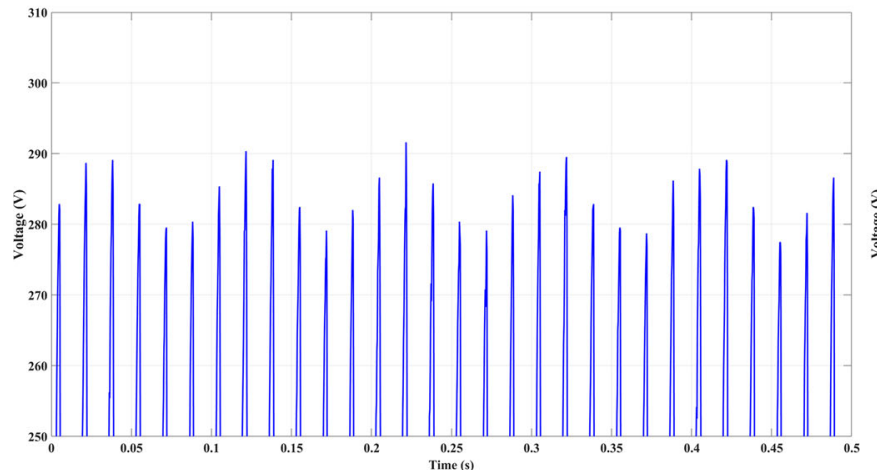

(e)

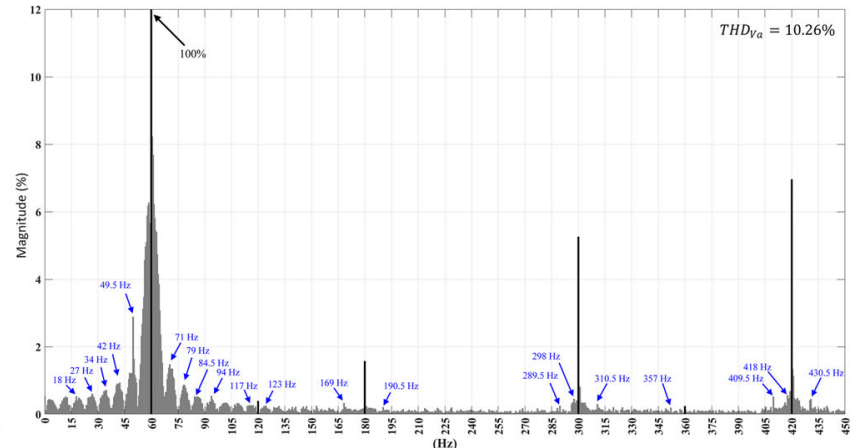

(b)

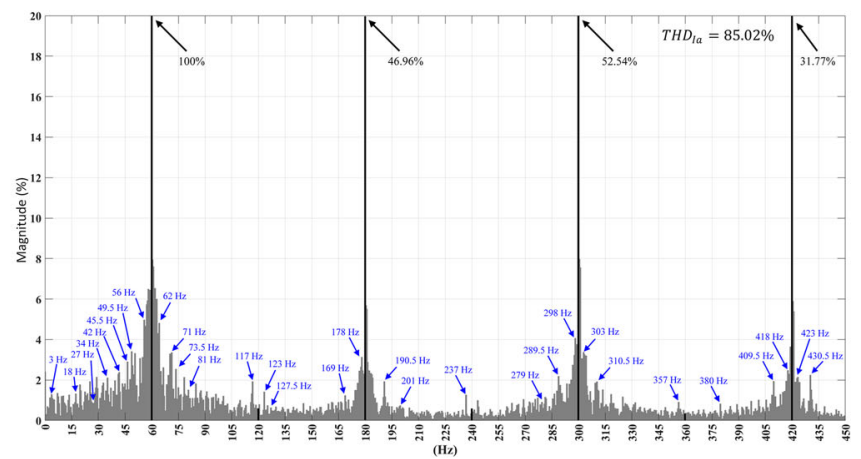

(d)

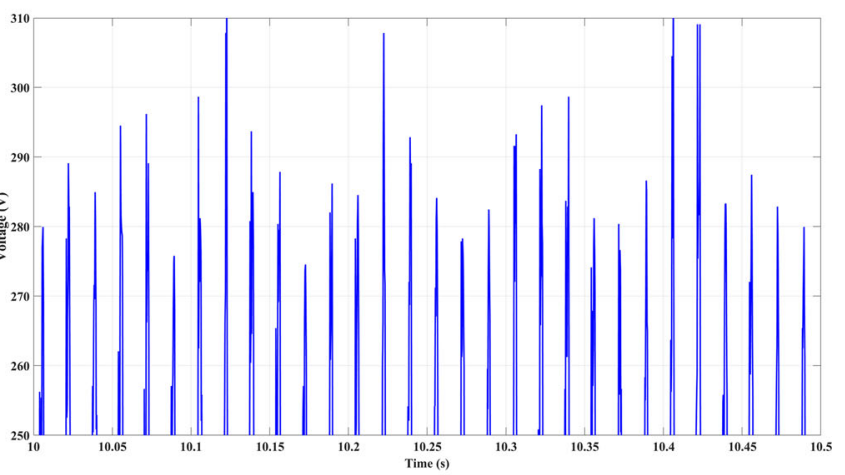

(f)

Fig. 15 Voltage and current spectra and voltage fluctuation at the inverter welding machine terminals: on the left, normal interval, and on the right, arcing interval

This is due to the components used in the machinery's construction (see Figs. 1, 5).

Figure 16, on the right, represents the CPT factors' trend for the inverter welding machine. Since the active power consumption increased for the welding condition, the power factor $(\lambda)$ increases and the distortion factor $\left(\lambda_{\mathrm{D}}\right)$ decreases. In any case (during the arcing period or not), these values are well below any limits established by power quality standards. Notice that during the arcing period, or off-period, this machine has more or less the same unbalanced factor $\left(\lambda_{N}\right)$ and reactivity factor $\left(\lambda_{Q}\right)$ values. These values are practically equal and are almost negligible.
This shows that the welding rectifier machine is much more disturbing than the rectifier machine. Therefore, the impact on the power system and power quality will also higher.

\section{Considerations for Interharmonics Analysis}

Conventionally, estimating the harmonic content of the voltage and current signals is based on using the discrete Fourier transform (DFT). IEC 61000-4-7 (2012) establishes that the signals are processed using the DFT with a 12 -cycle rect- 


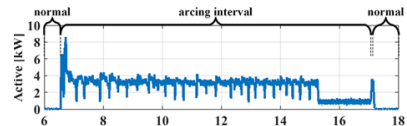

(a)

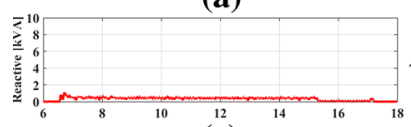

(c)

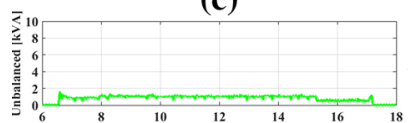

(e)

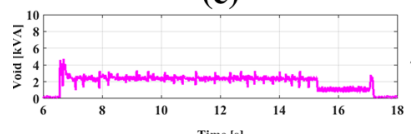

(g)

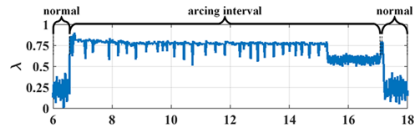

(b)

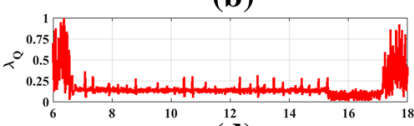

(d)

(f)

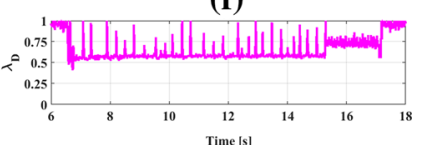

(h)

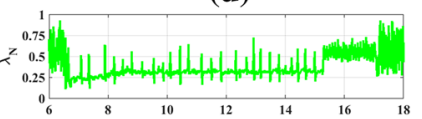

Fig. 16 CPT power terms (left) and load conformity factors (right) for the inverter welding machine

angular window of $60 \mathrm{~Hz}$, which results in a resolution at a frequency of $5 \mathrm{~Hz}$.

However, only by analyzing the frequency spectrum resulting from the decomposition of the signal under study, by applying the DFT, it is not possible to accurately identify the interharmonic components and their respective amplitudes. This is due to the fact that the spectrum leakage effects are intrinsic to the DFT formulation. In addition, a wrong choice of frequency resolution or even limitations of the measuring instrument can cause spectral leakage.

In the case of CPT, its formulation takes place in the time domain. Since the total current is composed of fundamental current and harmonics (14), the THD can be obtained without discriminating each harmonic and interharmonic, by calculating rms values of the signal, without the fundamental.

$i(t)=i_{\mathrm{f}}(t)+i_{\mathrm{h}}(t)=i_{\mathrm{fa}}(t)+i_{\mathrm{fr}}(t)+i_{\mathrm{h}}(t)$

where

$i(t)$ is the total current;

$i_{\mathrm{f}}(t)$ is the fundamental current;

$i_{\mathrm{h}}(t)$ is the harmonic current;

$i_{\text {af }}(t)$ is the fundamental active current;

$i_{\mathrm{rf}}(t)$ is the fundamental reactive current.

If we assume that the voltage is not too distorted $\left(\mathrm{THD}_{\mathrm{V}}<\right.$ $10 \%)$, when calculating the harmonic current $\left[i_{\mathrm{h}}(t) \cong i_{v}(t)\right]$ and its rms value $\left(I_{\mathrm{h}} \cong I_{v}\right)$ the total distortion can be calculated, including the effect of the subharmonic and interharmonic, as presented in (15):

$\operatorname{THD}_{I}=\frac{I_{\mathrm{h}}}{I_{\mathrm{f}}}=\frac{I_{\mathrm{h}}}{\sqrt{I_{\mathrm{fa}}^{2}+I_{\mathrm{fr}}^{2}}} \cong \frac{\lambda_{\mathrm{D}}^{2}}{1-\lambda_{\mathrm{D}}^{2}}$
From (15), notice that the CPT's distortion factor (11) is closely related to $\mathrm{THD}_{I}$.

\section{Conclusion}

Aiming to obtain corresponding waveforms and behaviors of real welding machines, two different computational models were proposed: (1) rectifier welding machine and (2) inverter welding machine. By comparing these models with experimental data, we demonstrated that these models can be considered suitable models for simulation studies. Therefore, these models can be very convenient in cases where the power utilities (or users) need to evaluate the connection impacts of welding machines to power systems, power quality studies, power factor correction, resonance analysis and time-varying harmonics evaluation.

In addition, CPT current/power terms and load conformity factors were used to evaluate and quantify the disturbances produced by the welding machines. The instantaneous current terms evaluated which disturbances are generated by the welding machines, and the collective rms values of the current terms represent how much of the total current is generated with reactive, unbalanced and nonlinearities, respectively. The power terms represent how much of the total energy has been lost to attend the reactive, imbalanced and harmonics demand of the machines. The load conformity factors represent particular (decoupled) machine characteristics (phase shift between the voltages and currents, imbalances and nonlinearities between voltages and currents). These values are related to the entire three-phase circuit (equivalent circuit).

Thus, it can be concluded that, unlike the inverter machine, the rectifier machine under normal operation conditions has a higher disturbing effect. The rectifier welding machine, in the arcing interval, requires a large amount of active power and a large amount of reactive power. This high variation of the reactive power associated with the production of interharmonics of this type of load results in voltage fluctuation in the terminals of this equipment. In addition to the issue of reactive consumption, imbalances and harmonics are also a problem in this interval.

The inverter welding machine generates high levels of current distortion during the arcing interval, which may cause resonance excitation, as well as the issue of imbalances. The results show that this equipment does not produce a large variation of significant reactive power. However, the supply voltage is modulated due to the presence of interharmonic voltage components superimposed on the fundamental signal. Therefore, when compared, the impact on the PQ of the rectifier welding machine is higher than that of the inverter welding machine. 
Finally, the welding machines' disturbances can even propagate into the grid, damaging other consumers connected at this point and have a direct impact on the power quality of the interconnected power system.

Acknowledgements The authors gratefully acknowledge the contributions of São Paulo Research Foundation (FAPESP) under Grant 2016/08645-9 for their financial support toward the development of this research.

\section{References}

Aksoy, I. (2014). A new PSFB converter-based inverter arc welding machine with high power density and high efficiency. Turkish Journal of Electrical Engineering and Computer Sciences, 22(6), 1501-1516.

Baggini, A. (2008). Handbook of power quality (1st ed.). London: Wiley.

Buso, S., Spiazzi, G., Mela, F., \& Fasolo, S. (2009). Design of an active load for electronic welding machines. In Twenty-fourth annual IEEE applied power electronics conference and exposition (pp. 1647-1653).

Casanueva, R., Azcondo, F. J., Díaz, F. J., \& Brañas, C. (2011). TIG welding machines. IEEE Industry Applications Magazine, 17(5), 53-58.

CPFL. (2000). Norma técnica - Critério para Atendimento a Máquina de Solda. CPFL Energia, Documento n. 238, Versão 1.0.

CPFL. (2012). Norma técnica - Requisitos para Conexão de Cargas Potencialmente Perturbadoras ao Sistema Elétrico da CPFL. CPFL Energia, Documento n. 10099, Versão 1.3.

CST 250 Owner's Manual. (2017). https://www.millerwelds.com/. Accessed 05 May 2017.

Das, J. C. (2015). Power system harmonics and passive filter designs (1st ed.). London: Wiley.

De La Rosa, F. C. (2006). Harmonics and power systems (1st ed.). Boca Raton: CRC Press.

Elektro. (2013). Norma técnica - ND 50 Ligaçães de Máquinas de Solda nas Redes de Distribuição de Energia Elétrica. Elektro Redes S. A.

IEC. (2004). Limits for harmonic current emissions. International Electro Technical Commission Standard, 61000-3-2.

IEC. (2012). Testing and measurement techniques-general guide on harmonics and interharmonics measurement and instrumentation, for power supply systems and equipment connected thereto, International Electro Technical Commission Standard, 61000-4-7.

IEEE. (2010). Standard definitions for the measurement of electric power quantities under sinusoidal, nonsinusoidal, balanced or unbalanced conditions. STD 1459-2010.

IEEE. (2014). Recommended practice and requirements for harmonic control in electric power systems. IEEE Std 519-2014 (Revision of IEEE Std 519-1992).

IEEE. (2015). Recommended practice for the analysis of fluctuating installations on power systems. IEEE Std 1453-2015 (Revision of IEEE Std 1453-2011).

IEEE P519. (2015). IEEE draft guide for applying harmonic limits on power systems. IEEE P519.1/D12, 1-124.

Junior, A. J. P. R., Gondim, I. N., Junior, J. R. M., \& Delaliba, A. C. (2015). A practical electric arc furnace model for flicker assessment. Journal of Control, Automation and Electrical Systems, 26(1), 68-79.
Kallaste, A., Kutt, L., Bolgov, V., \& Janson, K. (2008). Reactive power compensation for spot welding machine using thyristor switched capacitor. In Power quality and supply reliability conference (pp. 241-245).

Ko, W. H., \& Gu, J. C. (2016). Design and application of a thyristor switched capacitor bank for a high harmonic distortion and fast changing single-phase electric welding machine. IET Power Electronics, 9(15), 2751-2759.

Lincoln, J. F. (2003). The procedure handbook of arc welding (14th ed.). Cleveland: Lincoln Electric.

Marafão, F. P., Liberado, E. V., Paredes, H. K. M., \& Silva, L. C. P. (2010). Three-phase four-wire circuits interpretation by means of different power theories. In International school on nonsinusoidal currents and compensation (pp. 168-173).

Marafão, F. P., Paredes, H. K. M., \& Silva, L. C. P. (2009). Critical evaluation of FBD, PQ and CPT current decompositions for fourwire circuits. In Brazilian power electronics conference (pp. 4957).

Norrish, J. (2006). Advanced welding processes: Technologies and process control (1st ed.). Sawston: Woodhead Publishing.

O'Brien, A. (2004). Welding handbook: Welding process, part 1 (9th ed.). Miami: American Welding Society.

Paredes, H. K. M., Marafão, F. P., Mattavelli, P., \& Tenti, P. (2012). Application of conservative power theory to load and line characterization and revenue metering. In IEEE international workshop on applied measurements for power systems (AMPS) proceedings (pp. 1-6).

Paredes, H. K. M., Marafão, F. P., \& Silva, L. C. P. (2009a). A comparative analysis of FBD, PQ and CPT current decompositions-Part I: Three-phase, three-wire systems. In IEEE Bucharest PowerTech (pp. 1-8).

Paredes, H. K. M., Marafão, F. P., \& Silva, L. C. P. (2009b). A comparative analysis of FBD, PQ and CPT current decompositions-Part II: Three-phase, four-wire systems. In IEEE Bucharest PowerTech (pp. 1-6).

Píccola 405 DC Instruction Manual. (2017). http://www.bambozzi. com.br/website/. Accessed 05 May 2017.

RMS Electronic Systems. (2017). Available RMS electronic systems. http://www.rms.ind.br/. Accessed 05 May 2017.

Silva, E. F., Macedo, J. R., Scotti, A., \& Oliveira, J. C. (2011). Power quality analysis of gas metal arc welding process operating under different drop transfer modes. In XI Brazilian power electronics conference (pp. 129-135).

Souza, W. A., Liberado, E. V., Silva, L. C. P., Paredes, H. K. M., \& Marafão, F. P. (2013). Load analyser using conservative power theory. In International school on nonsinusoidal currents and compensation (pp. 1-6).

Tenti, P., Costabeber, A., Mattavelli, P., Marafão, F. P., \& Paredes, H. K. M. (2014). Load characterization and revenue metering under non-sinusoidal and asymmetrical operation. IEEE Transactions on Instrumentation and Measurement, 63(2), 422-431.

Tenti, P., Mattavelli, P., \& Paredes, H. K. M. (2010). Conservative power theory, sequence components and accountability in smart grids. In International school on nonsinusoidal currents and compensation (pp. 37-45).

Tenti, P., Paredes, H. K. M., \& Matavelli, P. (2011b). Conservative power theory, a framework to approach control and accountability issues in smart micro-grids. IEEE Transactions on Power Electronics, 26(3), 664-673.

Tenti, P., Paredes, H. K. M., Marafão, F. P., \& Matavelli, P. (2011a). Accountability in smart microgrids based on conservative power theory. IEEE Transactions on Instrumentation and Measurement, 60(9), 3058-3069. 
Vaidya, T. G. (2014). Application of active load balancer in spot welding machine loads. In IEEE International conference on power electronics, drives and energy systems (PEDES) (pp. 1-4).

Wang, J. M., \& Wu, S. T. (2015). A novel inverter for arc welding machines. IEEE Transactions on Industrial Electronics, 62(3), $1431-1439$.
Wang, J. M., Wu, S. T., Yen, S. C., \& Chiu, H. J. (2011). A simple inverter for arc-welding machines with current doubler rectifier. IEEE Transactions on Industrial Electronics, 58(11), 5278-5281.

Yang, X. X., \& Kratz, M. (2009). Power system flicker analysis by RMS voltage values and numeric flicker meter emulation. IEEE Transactions on Power Delivery, 24(3), 1310-1318. 